Cuad. Invest. Filol., 44 (2018), 45-66. http://doi.org/10.18172/cif.3413

\title{
PROSODIA Y GESTUALIDAD Y SU RELACIÓN CON LA EXPRESIÓN DEL HUMOR EN EL DEBATE PARLAMENTARIO ${ }^{1}$
}

\author{
Alejandro Romero Nieto \\ Universidad Complutense de Madrid \\ aromeronieto83@gmail.com
}

\begin{abstract}
RESUMEN: En el presente trabajo se analizan la gestualidad y la prosodia de un hablante politico durante un debate parlamentario desde el punto de vista de la expresión del humor. El objeto de este análisis es comprobar si el hablante marca de manera significativa, prosódica o gestualmente, sus enunciados humorísticos durante sus intervenciones en la cámara de diputados. El estudio se centra en un único hablante, el diputado socialista Antonio Miguel Carmona, de quien se han seleccionado una serie de ejemplos audiovisuales tomados de las grabaciones de los plenos de la Asamblea de Madrid. Las conclusiones que se extraen es que el rasgo prosódico que distingue el habla seria de la humorística es el tono y que no existe una relación clara entre los movimientos corporales del hablante parlamentario y la manifestación del humor.
\end{abstract}

PALABRAS CLAVE: prosodia, gestualidad, humor, debate parlamentario, análisis del discurso, politica.

\section{PROSODY AND GESTURE AND THEIR RELATION WITH THE EXPRESSION OF HUMOUR IN THE PARLIAMENTARY DEBATE}

\begin{abstract}
In this paper we present the analysis of the gesture and prosody of a political speaker during a parliamentary debate from the point of view of the expression of humour. The purpose of this analysis is to verify if the speaker marks in a significative way, either prosodically or gestually, his humorous utterances during his interventions in the Chamber of Deputies. The analysis focuses on a single speaker, socialist deputy Antonio Miguel Carmona, from whom a series of audio-visual examples taken from the recordings of plenary sessions of the Assembly of Madrid has been selected. The conclusions drawn are that the prosodic feature that distinguishes serious speech from
\end{abstract}

1. El presente trabajo es una reformulación de un capítulo de la tesis doctoral titulada "El humor en el discurso parlamentario: análisis pragmalingüístico de los debates de la Asamblea de Madrid", defendida en la Universidad Complutense de Madrid en febrero de 2017. 
humorous is the pitch and that there is no clear relationship between the body movements of the parliamentary speaker and the manifestation of humour. KEYWORDS: prosody, gesture, humour, parliamentary debate, discourse analysis, politics.

Recibido: 10/09/2017. Aceptado: 01/02/2018

\section{Introducción}

En el presente trabajo se expone un somero análisis de los rasgos prosódicos y gestuales en relación con la expresión del humor por parte de un hablante político en el transcurso de su actividad parlamentaria, en concreto Antonio Miguel Carmona, diputado socialista de la Asamblea de Madrid entre los años 2011 y 2015. La novedad de este análisis reside en tres aspectos. El primero es que el hablante pertenece a un ámbito sobre el que se han realizado pocos estudios relativos a la gestualidad y la prosodia, como es la política española. Asimismo, los trabajos que analizan la expresión corporal y los rasgos prosódicos de los políticos españoles se han centrado sobre todo en las entrevistas televisivas, y son muy escasos aquellos que analizan dichos rasgos considerando al político como sujeto parlamentario. El último de los aspectos relevantes de este estudio es que, simultáneamente a los rasgos cinéticos y prosódicos, se analiza la presencia o ausencia de la activación, a través de ellos, de un presunto marco humorístico.

En lo referente al estado actual de la cuestión cabe añadir que es numerosa la bibliografía sobre entonación lingüística, aunque la mayoría de los textos se ciñen al ámbito anglosajón. Solo en fechas relativamente recientes han comenzado a aparecer trabajos importantes referentes al ámbito hispánico, donde destacan los de García Riverón (1996-1998), Rao (2006) Hidalgo Navarro (2011) o Becerra Valderrama (2012). Por lo que respecta a la relación entre prosodia y afectividad, el panorama no es muy diferente: la mayoría de los trabajos analizan muestras de inglés oral, algunos genéricamente (Wichmann 2000) y otros específicos del humor y la ironía (Bertrand y Priego-Valverde 2011); y, dentro de ellos, son muy escasos los relativos al ámbito hispánico (Acuña Ferreira 2011).

En cuanto a la bibliografía que se ocupa de la relación entre prosodia y política, existe una larga tradición de estudios acerca de los rasgos fónicos de los discursos de políticos angloparlantes, con textos ya clásicos como los de Atkinson (1988), Wilson (1990) o Lakoff (1990). Únicamente durante los últimos quince años han visto la luz trabajos que han servido para llenar el hueco que existía en 
el análisis del discurso de políticos no anglosajones, como Archakis y Tsakona (2011) o Mueller (2011), relativos a los debates en los parlamentos griego y alemán respectivamente; o Nieto y Otero (2008), Hidalgo Downing (2009) e Hidalgo Downing y Nieto y Otero (2014), que ponen el foco en los discursos emitidos por políticos de habla hispana. Con todo, son necesarias más investigaciones que den cuenta de la relación existente entre la prosodia y la afectividad en el campo específico del discurso político en el ámbito hispánico.

En lo relativo a la comunicación no verbal, el panorama bibliográfico es bastante heterogéneo. Por un lado, tenemos trabajos pormenorizados que analizan el fenómeno de manera genérica (Birdwhistell 1979, Davis 2010, Cestero Mancera 2015), aunque la mayoría de ellos se centran en la comunicación no verbal de hablantes británicos y estadounidenses. Paralelamente, existen, aunque no muy numerosos, textos más específicos que tienen por objetivo analizar la relación que existe entre la comunicación no verbal y la afectividad, en concreto en lo que respecta a la expresión del humor y la ironía por parte de hablantes de inglés nativos (Attardo et al. 2003). Asimismo, también son escasos los textos donde se analiza la gestualidad de los españoles en la interacción cotidiana, como Cabañas Martínez (2005), Becerra Valderrama (2012) o Cestero Mancera (2015). Y lo mismo podemos afirmar sobre los trabajos destinados a estudiar gestualidad de los políticos, tanto en el ámbito anglosajón (Atkinson 1988, Charteris-Black 2007) como en el español (Hidalgo Downing 2009), aunque ninguno de ellos menciona nada acerca del papel que juega la comunicación no verbal durante los debates parlamentarios.

Con respecto a los trabajos sobre gestualidad en el discurso político, la mayoría de ellos coinciden en que esta varía en función del tipo de género o subgénero en el que participe el hablante. Por ejemplo, dentro del mitin, la gestualidad desempeña un papel muy importante como factor de persuasión, debido a dos razones: por un lado, este género se construye como si fuera un evento teatralizado, y en su desarrollo entran en juego aspectos como la puesta en escena, la posición física, la expresión facial, los movimientos de las manos, etc. (Ghiglione 1994, Cruces y Díaz de Rada, 1995); por otro, el ethos interaccional (Spencer-Oatey 2008) que manifiesta el hablante político durante un mitin es el de la espontaneidad, pues está dirigiéndose sobre todo a una audiencia formada por votantes y simpatizantes de su partido, es decir, destinatarios con los que mantiene lazos de camaradería que le permiten desenvolverse con cierta libertad. Por contra, durante los debates cara a cara y los discursos parlamentarios, la gestualidad y los movimientos faciales no suelen ser muy abundantes, pues ambos son eventos donde la forma de interactuar de los participantes está fuertemente reglada, ya sea por las directrices establecidas 
de antemano por un determinado canal de televisión, en el caso del debate cara a cara, ya sea por el reglamento de la Cámara de Diputados, en el caso del debate parlamentario (Pérez de Ayala 2001, Saftoiu y Popescu 2014).

\section{Marco teórico}

El estudio de los rasgos suprasegmentales del humor ha contado con el interés de la comunidad científica tan sólo en época muy reciente. Los trabajos más antiguos no tienen más de cuarenta años y poseen la peculiaridad de basar su análisis en textos literarios declamativos. Quizás esto sea debido, por un lado, a la peculiar categorización del propio término "humor"'; y por otro, a la falta de medios técnicos y humanos para llevar a cabo experimentos fonéticos y fonológicos lo suficientemente exhaustivos como para dar buena cuenta del fenómeno. Por ello, no será hasta finales de los 90, aprovechando el auge de la informática, cuando empecemos a contar con trabajos exhaustivos sobre la entonación del humor y, específicamente, de la ironía, entendida como una realización concreta de humor (Pickering et al. 2009, Attardo y Pickering 2011, Attardo et al. 2011, Flamson et al. 2011). Unos trabajos que, además, tienen la ventaja, a diferencia de los anteriores, de que analizan datos extraídos de conversaciones reales.

Es en Attardo y Pickering (2011) donde encontramos el primer estudio pormenorizado del tempo en los chistes. Su trabajo refutó la llamada teoría popular del tempo, que sostenía, entre otras cosas, que los remates de los chistes se producían a una velocidad de habla más rápida que la habitual o en un tono más alto y con mayor volumen que el habitual, así como de forma entrecortada y con una pausa previa. Tras realizar, mediante un software informático, el análisis acústico de un corpus de datos formado por diecinueve chistes espontáneos y un chiste preparado ad hoc por los investigadores llegaron a unas conclusiones realmente significativas. En primer lugar, los remates se producían a la misma velocidad que el resto del chiste. Por otro lado, vieron que se solía producir una pausa entre el cuerpo del chiste y el remate. Asimismo, los remates en estilo directo no influían tampoco en la velocidad de la expresión del chiste. También descubrieron que los hablantes cometían errores constantes a la hora de contar chistes (autocorrecciones, vacilaciones, etc.) debido a que tenían en mente un modelo de enunciado ideal al que pretendían aproximarse durante su alocución. Por último, afirmaban que, por lo que respecta a su desarrollo, no había diferencia entre los chistes espontáneos y los preparados.

2. Attardo define el humor como un término paraguas, en el sentido de que es un fenómeno en cuya caracterización entran en juego aspectos procedentes de muchas disciplinas. 
También es significativo por la exhaustividad de su análisis el trabajo de Attardo et al. (2011) relativo al análisis de la prosodia y los rasgos suprasegmentales del humor conversacional, cuyas características son distintas a las del humor no conversacional ${ }^{3}$. Attardo y sus colaboradores se preguntan si estas diferencias estructurales se reflejan en la prosodia y si los hablantes marcan de alguna manera este tipo de humor, especialmente por lo que respecta a las reacciones de estos hacia el contenido proposicional de los enunciados. El corpus de datos sobre el que basaron su estudio estaba formado por una serie de diálogos informales realizados por estudiantes voluntarios de una universidad del Medio Oeste estadounidense. Su objetivo era averiguar si existía alguna diferencia, en cuanto a tono y volumen, entre las partes serias y las humorísticas de los enunciados emitidos durante el diálogo, y descubrieron que, en realidad, había homogeneidad entre ambas. Posteriormente, quisieron comprobar si se producían diferencias relevantes entre los enunciados conversacionales de su estudio y los analizados en Pickering et al. (2009). Como conclusión final extrajeron que la única diferencia entre el humor conversacional y el prefijado está en los remates ${ }^{4}$ : en los primeros no encontraron un descenso significativo en el tono, cosa que sí sucedía con los ejemplos del corpus de Pickering et al. (2009). La explicación que proporcionaron Attardo y sus colaboradores fue que en el humor narrativo el remate suele coincidir justo con el cierre de la frase, que generalmente se realiza en un tono descendente: "Los resultados de este estudio son consistentes con la explicación de que la posición al final de un paratono explica el significativo descenso tonal de los remates." (Attardo et al. 2011: 233).

La aplicación de este análisis al ámbito hispánico la encontramos en Hidalgo Navarro (2011), donde se analizan dos ejemplos de conversaciones humorísticas coloquiales procedentes del corpus de datos del grupo Valesco 5 . En este trabajo

3. En este estudio también se van a tener en cuenta ejemplos de ironía, al tratarse esta de un tipo de humor no preparado.

4. Attardo y sus colaboradores distinguen entre el remate de los chistes narrativos y el del humor conversacional: al primero lo denominan punch line y al segundo jab line (punch en inglés significa puñetazo, mientras que jab es un tecnicismo que se emplea en el boxeo para referirse a los puñetazos directos). Con todo, las diferencias estructurales entre ambos no son relevantes, por lo que se ven como un mismo elemento que aparece representado de dos formas distintas en dos contextos distintos.

Con respecto a este trabajo, y puesto que en español no existen términos que nos permitan precisar la diferencia entre golpes directos y genéricos, se ha optado por denominarlos a ambos remates.

5. El grupo Valesco (Valencia Español Coloquial) es un grupo de investigación nacido en 1990 en la Universidad de Valencia, dirigido por el profesor Antonio Briz y formado por investigadores y becarios de Lengua Española de las universidades de Valencia y Alicante. Aquí el enlace a su página web: http:// www.valesco.es/web/index.html. 
se extraen las mismas conclusiones que en Attardo et al. (2011): los rasgos prosódicos no actúan como marcas características del humor fuera de un contexto determinado: "[...] debe considerarse que la interpretación de los factores prosódicos como desencadenantes de efectos humorístico-intensificadores está fuertemente determinada por el contexto que envuelve a la emisión lingüística, ya sea léxico [...], ya sea semántico" (Hidalgo Navarro 2011: 288)6

Así pues, a raíz de lo expuesto en este apartado, hemos de admitir que no existe un tono humorístico como tal ${ }^{7}$, es decir, no existen rasgos prosódicos que, por sí solos, sean capaces de discriminar los casos humorísticos de los no humorísticos. La entonación del humor va a depender, por tanto, de tres aspectos: por un lado, de las características prosódicas de la lengua en que se encuadra el enunciado; por otro, de la posición de este en el decurso del intercambio lingüístico (como apertura o conclusión de una conversación, como respuesta a un enunciado previo, etc.); y por último, del estilo del narrador, quien, dependiendo de su velocidad de habla, de su pericia a la hora de desarrollar el enunciado humorístico, etc. será en última instancia quien establezca las características fónicas del chiste o juego de ingenio en cuestión.

Por otro lado, muchos de estos trabajos distinguen entre la prosodia del humor y la de la ironía, entendida como una realización específica de humor, con unas características particulares ${ }^{8}$. En lo que respecta a la prosodia irónica, las cosas parecen más claras a raíz de los experimentos realizados, que, pese a todo, han sido escasos: hay un consenso más o menos amplio al considerar la entonación como el principal indicador prosódico de habla irónica ${ }^{9}$. Con todo, hay analistas que se desmarcan de esta opinión, como Bryant (2011), para quien, pese a considerar que sí existe una diferenciación prosódica entre

6. No obstante, tal y como indica el propio Hidalgo, son necesarios estudios más detallados acerca del funcionamiento de los rasgos suprasegmentales del humor conversacional en español.

7. Si sondeamos la bibliografía encontramos trabajos que defienden que, efectivamente, el tono humorístico existe como rasgo distintivo independiente (Purandare y Litman 2006, Urios-Aparisi y Wagner 2011). No obstante, los resultados de estos estudios hay que tomarlos con cierta cautela, pues sus análisis no se realizan sobre corpus elaborados a partir de actos de habla espontánea, sino sobre enunciados extraídos de comedias de situación estadounidenses en donde encontramos a unos hablantes/actores que se dirigen a un público heterogéneo con el que no están familiarizados, y, en consecuencia, se ven obligados a marcar prosódicamente sus enunciados humorísticos para que resulten efectivos.

8. La idea principal de todos estos trabajos se basa en la hipótesis en que la incongruencia entre lo que se dice y la forma de decirlo sirve como pista hacia el oyente para detectar la ironía del hablante. Sin embargo, esta cuestión, tal y como señalan Bryant y Fox Tree (2002), es bastante discutible, pues no está apoyada en estudios empíricos.

9. La clasificación de las distintas formas en las que se puede manifestar este tono irónico la encontramos en Attardo et al. (2003). 
el habla seria y la no seria, niega la existencia de un tono irónico como tal y es más partidario de la manifestación de una forma de hablar específica destinada a romper la desambiguación, ligada al contenido emocional que imprime el hablante irónico a su enunciado ${ }^{10}$. También es significativo el aporte de Bryant y Fox-Tree $(2002,2005)$, en cuyos trabajos se analizan, siguiendo los postulados de la teoría de la relevancia, una serie de conversaciones radiofónicas que resultan ambiguas en el contenido pero claras en la forma, y se llega a la conclusión de que, a falta de otro tipo de estímulos, los rasgos suprasegmentales constituyen el principal indicador de ironía. Asimismo, algunos rasgos faciales o cinéticos han sido vistos como indicadores de comportamiento irónico. Attardo et al. (2003) señalan entre los principales la sonrisa; el movimiento de cejas hacia arriba o hacia abajo; los ojos abiertos de par en par, entrecerrados, o parpadeantes; la cabeza; o la llamada "cara de póker"

Con respecto al ámbito hispánico, es especialmente interesante el estudio sobre los patrones fónicos de la ironía en el español estándar realizado por el grupo Griale ${ }^{12}$, que analiza muestras de lengua coloquial extraídas del corpus Valesco. En función de una serie de análisis fonéticos y fonológicos realizados sobre las muestras del corpus, el grupo Griale sostiene que existen cuatro tipos distintos de enunciación irónica, cada una dependiente de una determinada estrategia discursiva del hablante (Padilla García 2009, Attardo et al. 2003). Por tanto, sí que podemos hablar de la existencia de un tipo de entonación específicamente irónica que permite distinguir unos enunciados de otros. Dicha entonación, no obstante, depende tanto de la intención comunicativa del hablante como de la relación de intimidad que mantengan entre sí los interlocutores, que será lo que, a la postre, termine por caracterizar el acto de habla irónico.

10. Esta idea no es incompatible con la existencia de unos patrones prosódicos característicos de la ironía, ya sean estos genuinos, ya estén producidos por la combinación de factores ajenos.

11. Según Attardo et al. (2003), algunos autores creen que estos rasgos prevalecen sobre los puramente gramaticales como indicadores de ironía. Sin embargo, estudios recientes han demostrado justamente lo contrario. Para más detalle al respecto, véase Attardo et al. (2003).

12. Griale es el nombre que se le da al Grupo de Investigación sobre Ironía y Humor en Español de la Universidad de Alicante, una agrupación de profesores de dicha institución cuyos objetivos principales son el análisis pragmático de la ironía y el humor, la observación de aspectos socioculturales como el género y su incidencia en la ironía y el humor, la adquisición del humor en niños y la aplicación de los resultados obtenidos a la enseñanza-aprendizaje del español como lengua extranjera y a los trastornos del lenguaje, en especial a los que tienen que ver con el espectro autista. El enlace a su página web es: http://griale.dfelg.ua.es. 
En esta misma línea, también fue el grupo Griale quien propuso una exhaustiva clasificación de la gestualidad del fenómeno. Basándose siempre en el corpus Valesco, establecen tres tipos de marcas gestuales: marcas kinésicas, marcas proxémicas y marcas paralingüísticas (Cestero Mancera 2009). Asimismo, en Attardo et al. (2003) se hace alusión a una marca irónica no verbal que, a su juicio, no ha sido tenida en cuenta en la bibliografía especializada hasta la fecha: la "cara de póker": "Con 'cara de póker' nos referimos a una expresión facial que puede describirse de forma intuitiva como inexpresiva, inmóvil y falta de emoción" (Attardo et al. 2003: 54).

\section{Metodología y descripción del corpus}

Con respecto a la metodología, se ha optado por seguir la línea de análisis de trabajos como Hidalgo Downing (2009) o Hidalgo Downing y Nieto y Otero (2014), donde se estudian los mecanismos de vinculación afectiva en el debate político siguiendo un enfoque funcional e integrado, en el que se examinan tanto los mecanismos lingüísticos de la afectividad, como su expresión fónica, obteniendo así un análisis combinado de los dos aspectos ${ }^{13}$.

En lo relativo al corpus del presente trabajo, este está compuesto por 362 documentos escritos en soporte electrónico (archivos .pdf) que recogen la transcripción literal de las reuniones celebradas en la Asamblea de Madrid durante el periodo que va desde el 1 de enero de 2010 hasta el 31 de diciembre de 2011, ambos inclusive ${ }^{14}$ : el denominado Diario de Sesiones, al cual se puede acceder libremente a través de la página web de la Asamblea de Madrid ${ }^{15}$. De entre todos ellos he seleccionado un total de 73 sesiones, constituidos de la siguiente manera: 30 plenos (entre los que hay una monográfica, tres debates

13. Concordamos plenamente con estas autoras en la consideración del humor como un fenómeno funcional y por tanto en la necesidad de estudiar los dos aspectos de forma integrada.

14. Durante este periodo, España, y en especial la Comunidad de Madrid, conoció una situación política bastante particular: la presidencia de la Comunidad Autónoma de Madrid era del Partido Popular (PP), con Esperanza Aguirre a la cabeza, siendo el Partido Socialista (PSOE) el principal grupo de la oposición, con Tomás Gómez Franco como Secretario General. A nivel nacional, en cambio, tenía lugar la situación opuesta: el PSOE, con José Luis Rodríguez Zapatero como líder, era el partido gobernante, mientras que el PP, con Mariano Rajoy al frente, ejercía las labores de principal partido de la oposición. Por ello, en la Asamblea de Madrid se establecieron unas relaciones políticas con el gobierno central bastante tensas, que tuvieron su lógico reflejo en las diferentes intervenciones de los diputados.

15. http://www.asambleamadrid.es/ES/default.aspx. 
y un debate de investidura), 41 comisiones y 2 diputaciones permanentes. En total, han sido unas 5053 páginas, correspondientes a 308 horas y 20 minutos de comparecencias.

Los criterios que se han empleado a la hora de discriminar los enunciados humorísticos de los no humorísticos han sido dos. El primero ha consistido en la indicación en la transcripción de la aparición de risas entre el auditorio, en concreto entre los partidarios del hablante ${ }^{16}$. Puesto que la risa no es siempre un indicador de la presencia humor, el segundo de los criterios en que nos hemos basado ha sido la intención clara del hablante de realizar humor. Esta intención clara se pone de manifiesto a través de algún tipo de desviación, formal o de contenido, con respecto a lo considerado como normalizado, o habitual, dentro del contexto enunciativo, en este caso un debate parlamentario ${ }^{17}$ : una expresión con doble sentido, una exageración formal, una digresión con respecto al tema que se está debatiendo, etc. ${ }^{18}$

El análisis prosódico ha sido realizado sobre 25 enunciados: 13 de tono humorístico y 12 de tono no humorístico. Todos salvo uno han sido agrupados en pares de enunciados, a fin de hacer más efectivo el estudio comparativo. En la selección de los pares se han seguido criterios puramente estructurales: se han buscado enunciados serios cuya forma o longitud coincidiese con la de su contraparte humorística, para que el estudio comparativo fuese lo más preciso posible. Entre ellos hay preguntas retóricas, aclaraciones, afirmaciones, órdenes, exclamaciones e incluso un chiste. Los pares de enunciados proceden de las grabaciones audiovisuales de los plenos de la Asamblea de Madrid, a las cuales se puede acceder gratuitamente en la sección "Asamblea abierta" de la página

16. Los enunciados del corpus que provocaban risa entre los adversarios del hablante no podían ser considerados humorísticos, pues se trataba de actos de habla ofensivos, generalmente amenazas o insultos, donde la risa no actuaba como respuesta al enunciado humorístico, sino como mecanismo de mitigación o desprecio de la ofensa

17. Está asumido por los analistas que el humor activa un entorno o marco específico que posee sus propios patrones de comportamiento, los cuales se desmarcan claramente de los del entorno serio o no-humorístico en el que se desarrolla la vida real. Para más detalle, véanse Bernárdez (1984), Norrick (1993), Charaudeau (S. D.) o Chafe (2007).

18. Hemos optado por estos criterios porque nos parecieron lo suficientemente objetivos como para realizar un análisis serio, toda vez que el corpus sobre el que hemos trabajado está elaborado a partir de textos escritos y, por lo tanto, carentes de cualquier rasgo paraverbal que pudiera ayudarnos a proporcionar una interpretación más fiel de los mismos. Es cierto que a lo largo de las transcripciones aparecieron numerosos enunciados que, aunque nos resultaban hilarantes, no había evidencias de que hubieran desencadenado risas entre el auditorio. Por ello, consideramos que era demasiado subjetivo tener en cuenta dichos enunciados como humorísticos y, en consecuencia, preferimos apartarlos del análisis. 
web de dicha institución. Ha sido un total de 30 grabaciones, correspondientes a unas 245 horas y 53 minutos de comparecencias. El sujeto hablante del que proceden todos ellos es el diputado Antonio Miguel Carmona, del Grupo Parlamentario Socialista. La elección de este sujeto ha obedecido a criterios puramente cuantitativos: ha sido el hablante que más veces ha intervenido a lo largo de las diferentes sesiones plenarias y, en consecuencia, aquel del que más ejemplos se han podido extraer.

Una vez aisladas las muestras de habla oral, se ha realizado un análisis acústico de las mismas a través del software Praat. Las serias han sido comparadas con las humorísticas a partir de los tres parámetros habituales en todo análisis acústico: el tono, o "la impresión auditiva que percibimos de la frecuencia fundamental" (Quilis 1993: 94) y se mide en hertzios (Hz.); la intensidad, o "la potencia acústica que se transmite a través de una superficie" (Quilis 1993: 91) y se mide en decibelios (dB); y el tempo, o velocidad a la que transcurre un enunciado y se mide en sílabas por segundo (S/S). De la frecuencia fundamental (f0) se han extraído dos valores: el rango y la media o registro. De la intensidad, únicamente se ha extraído la media de los rangos ${ }^{19}$.

Con respecto a los rasgos gestuales, el estudio se ha realizado sobre las mismas muestras seleccionadas para el análisis prosódico. En este caso, el análisis ha consistido en la comparación de una serie de secuencias grabadas en fotografía fija, extraídas de las grabaciones audiovisuales de las sesiones plenarias de la Asamblea de Madrid, en las que puede verse al diputado Carmona interviniendo como orador en la tribuna, durante su turno de palabra. La selección de las imágenes se ha realizado atendiendo a los mismos criterios que en el análisis prosódico: parejas de enunciados humorísticos y serios con las mismas características ilocutivas (afirmaciones, exclamaciones, preguntas, etc.).

No obstante, es necesario aclarar que, debido a las características del corpus empleado en el presente trabajo, no se ha podido acceder a un volumen de datos lo suficientemente amplio como para extraer resultados con valor estadístico, toda vez que las cámaras de diputados no son ámbitos en los que la aparición del humor sea algo frecuente.

19. El rango tiene que ver con la amplitud de movimiento de la onda sonora y se calcula mediante la diferencia entre los índices máximo y mínimo de los valores de una misma línea tonal dentro de un determinado enunciado. 


\section{Análisis de los datos y discusión}

A continuación se presenta una serie de gráficas en las que se pueden ver las oscilaciones de las líneas de frecuencia en azul e intensidad en verde, de los pares de enunciados sobre los que se ha trabajado. La muestra humorística aparece representada a la izquierda y su contraparte seria a la derecha. Bajo cada una de ellas aparecen indicados los índices máximos y mínimos de frecuencia e intensidad.

a) Afirmación humorística

"En el año 2011 para ustedes las ciudades más importantes del mundo son Nueva York, Parla, París...”

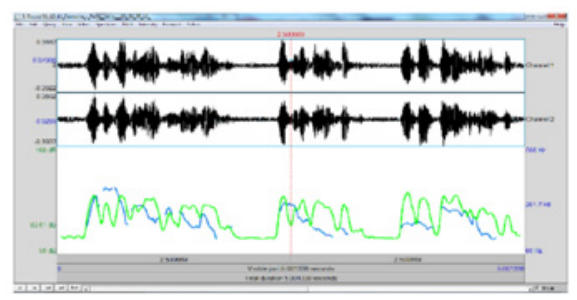

Índice máximo fo: $259.1 \mathrm{~Hz}$

Índice mínimo fo: $110 \mathrm{~Hz}$

Índice máximo int: $76 \mathrm{~dB}$

Índice mínimo int. 57,65 dB b) Afirmación seria

"No trato de hacer un discurso brillante. Trato de convencerle. Intelectualmente convencerle."

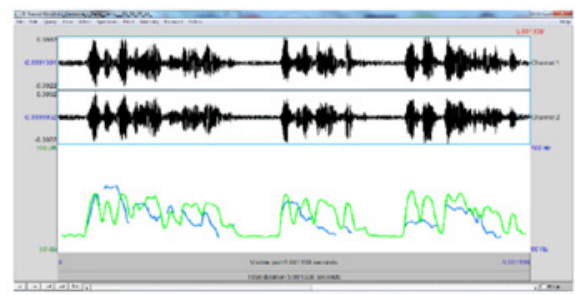

Índice máximo f0: $332 \mathrm{~Hz}$ Índice mínimo $f 0: 123,3 \mathrm{~Hz}$

Índice máximo int.: $78 \mathrm{~dB}$

Índice mínimo int.: $57,32 d B$

Gráfica 1. Comparativa afirmación humorística / afirmación seria

Como puede verse, el enunciado serio posee un rango de frecuencia superior al de su contraparte humorística. El rango de ambas intensidades, en cambio, es prácticamente idéntico, de manera que no podemos considerarlo un parámetro determinante.

Por lo que respecta a los valores máximos y mínimos del tono, en el ejemplo humorístico estos se alcanzan justo cuando el hablante está siendo más puramente irónico, es decir, en la enumeración del final: el máximo de f0 en la sílaba York y el mínimo de fo en la sílaba -rís de la palabra París, que coincide justo con el cierre de la frase. Puesto que este no es el patrón entonativo característico de una frase enunciativa-afirmativa, hemos de concluir que el hablante efectivamente está imprimiendo un valor afectivo específico a su enunciado humorístico. Por contra, el ejemplo serio mantiene los patrones tonales de una frase enunciativa-afirmativa: 
el máximo de la f0 se encuentra justo entre la segunda y tercera sílaba, es decir, durante la apertura de la frase; y el mínimo de la f0 se encuentra justo al cierre.

a) Exclamación humorística:

“'Eso es espionaje!”

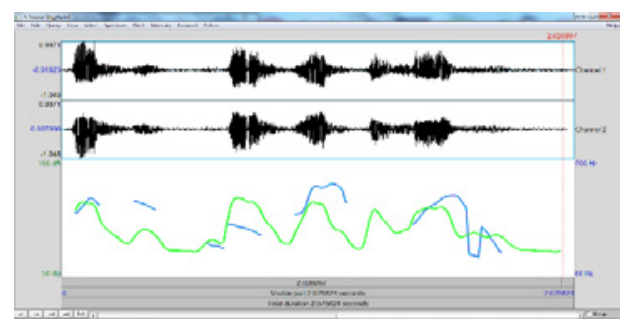

Índice máximo fo: $367 \mathrm{~Hz}$

Índice mínimo $f 0: 190,5 \mathrm{~Hz}$

Índice máximo int.: $85 d B$

Índice mínimo int.: $61,21 \mathrm{~dB}$ b) Exclamación seria

“Hace 200 años!”

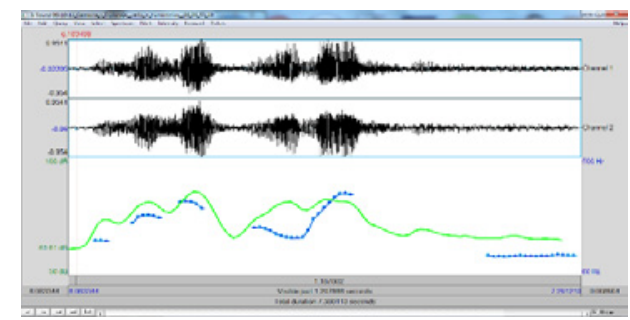

Índice máximo fo: $409 \mathrm{~Hz}$

Índice mínimo $\mathrm{f0}: 136 \mathrm{~Hz}$

Índice máximo int.: $86 \mathrm{~dB}$

Índice mínimo int.: $61,09 \mathrm{~dB}$

Gráfica 2. Comparación exclamación humorística / exclamación seria

En este par de ejemplos, nuevamente, el rango de la frecuencia fundamental del enunciado serio es superior al del humorístico. Y, nuevamente también, el rango de la intensidad es muy similar en ambos casos, de manera que tampoco podemos considerarla un rasgo distintivo determinante.

Por lo que respecta a los índices de la f0, lo anómalo se da otra vez en el caso humorístico: contrariamente a lo esperado, el valor máximo de la f0 no lo encontramos al inicio sino en la sílaba -na de espionaje, que es la de mayor carga connotativa de toda la construcción, y, por lo tanto, donde se encuentran realmente los valores emotivos/burlescos; el valor mínimo también se desmarca de lo esperado, pues corresponde a la sílaba $e$ - de la palabra eso, que abre el enunciado. Por contra, el ejemplo serio mantiene los rasgos tonales típicos de las oraciones exclamativas, pues empieza con unos valores de frecuencia muy altos (301-356 $\mathrm{dB}$ ) hasta alcanzar la cima en la sílaba -cien- de doscientos, para terminar descendiendo en el paratono, donde se alcanza el valor mínimo. Esto nos lleva de nuevo a concluir que el hablante está concentrando los recursos expresivos en una parte de su enunciado, haciendo coincidir la mayor prominencia tonal con el elemento que considera que puede crear en mayor medida el efecto humorístico. 
a) Aclaración humorística

"Yo, desde luego,

niego mi relación con Scarlett Johansson.

Diga lo que diga ella."

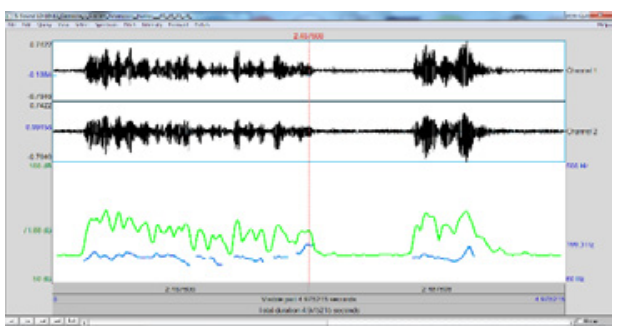

Índice máximo $f 0: 201 \mathrm{~Hz}$

Índice mínimo f0: $127,8 \mathrm{~Hz}$

Índice máximo int.: $80 \mathrm{~dB}$

Índice mínimo int.: $62,13 d B$ b) Aclaración seria

"Y lo hemos comentado algunos diputados y diputadas del Grupo Parlamentario Socialista."

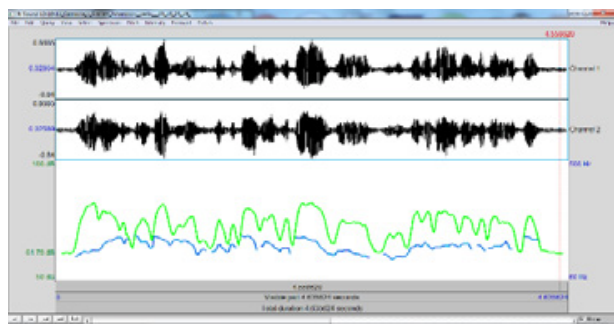

Índice máximo f0: $228 \mathrm{~Hz}$ Índice mínimo $\mathrm{f0}: 147,5 \mathrm{~Hz}$ Índice máximo int.: $82 \mathrm{~dB}$ Índice mínimo int.: $62,09 \mathrm{~dB}$

Gráfica 3. Comparación aclaración humorística / aclaración seria

En esta gráfica comparativa de nuevo se muestra la f0 como el rasgo prosódico distintivo entre ambos enunciados: el rango de la línea tonal del enunciado serio es superior al de la no seria. Por lo que respecta al rango de la intensidad, los valores son muy parecidos en ambos ejemplos, de manera que tampoco podemos considerarla un parámetro relevante en la diferenciación prosódica.

En cuanto a los valores máximos y mínimos, en el ejemplo no serio encontramos una línea tonal muy plana, típica de los llamados "chistes atonales", con únicamente dos subidas importantes que coinciden precisamente con las dos clausuras de las dos partes de las que se compone el enunciado: la primera, de $228 \mathrm{~Hz}$, justo en la sílaba son de Johansson; y la segunda, de 195,4 Hz, justo en ella. Esto es algo anómalo en los patrones tonales de las oraciones enunciativas, que se caracterizan por un descenso en sus cadencias, coincidiendo justo con el paratono. La aclaración seria, en cambio, posee una línea tonal mucho menos plana, así como un comportamiento más esperable: el pico máximo se alcanza justo en las sílabas -ta- y -dos de diputados, y el mínimo en del, coincidiendo justo con una pausa que el hablante realiza para respirar. Así pues, hemos de concluir nuevamente que el hablante está señalando prosódicamente de manera inequívoca su enunciado humorístico. 
a) Interrogación humorística

“ ¿Ustedes saben la cantidad de cosas que yo he leído en la prensa sobre ustedes?"

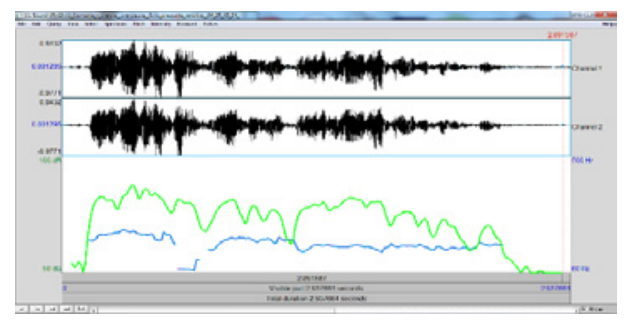

Índice máximo f0: 223,3 Hz

Índice mínimo $\mathrm{f0}: 70,42 \mathrm{~Hz}$

Índice máximo int.: $87 \mathrm{~dB}$

Índice mínimo int.: $50,57 \mathrm{~dB}$ b) Interrogación seria

“¿Y qué podemos pensar entonces si no se trata de ahorrar?"

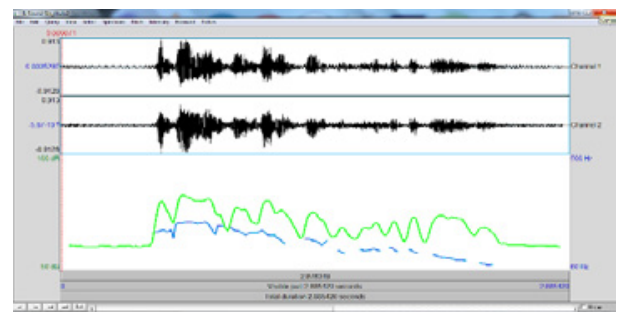

Índice máximo f0: $246 \mathrm{~Hz}$

Índice mínimo f0: $84,4 \mathrm{~Hz}$

Índice máximo int.: $82 \mathrm{~dB}$

Índice mínimo int.: $52,48 d B$

Gráfica 4. Comparativa interrogación humorística / interrogación seria

Como se ha comentado previamente, los dos pares de enunciados interrogativos que forman parte del corpus han supuesto una excepción a la tónica general, en el sentido de que el rango de las f0 de las partes humorísticas ha sido superior al de las partes serias. Esto es lo que ocurre en el presente ejemplo: pese a que existe una variación tonal entre el enunciado serio y su contraparte humorística, dicha variación se contrapone al resto de ejemplos no interrogativos, en los cuales el enunciado serio posee un rango de fo superior al no serio. En lo relativo a la intensidad, volvemos a ver que tanto el máximo como el mínimo son prácticamente idénticos en ambos casos.

Con respecto al comportamiento de las líneas tonales, vemos cómo el del enunciado serio es más previsible que el del humorístico, pues mantiene una progresión descendente, con el índice máximo en la secuencia de apertura, en la sílaba -mos de podemos, y el mínimo en la de clausura, justo coincidiendo con el paratono, en la sílaba -rar de ahorrar. Sin embargo, la línea tonal de la parte humorística es más uniforme, con ambos índices durante la secuencia de apertura: el máximo, en la sílaba -ben de saben; y el mínimo, durante la sílaba can- de cantidad. Por lo tanto, se advierte de nuevo que el hablante realiza una distinción prosódica entre sus interrogaciones retóricas serias y no serias, con la intención de proporcionar al auditorio indicios claros de que, efectivamente, está produciendo un enunciado humorístico. 
Por lo tanto, no hay duda de que el hablante parlamentario marca prosódicamente de en el rango del tono. Como se ha expuesto previamente, el cometido de esta estrategia es reforzar el valor expresivo del enunciado, a fin de proporcionar a su audiencia pistas inequívocas de la aparición del humor y, en consecuencia, evitar que su comunicación sea infructuosa. Por consiguiente, el papel que desempeñan las pistas prosódicas en el contexto parlamentario es decisivo, pues el hablante desarrolla su discurso en un entorno serio y fuertemente reglado.

Pese a que, como ya se ha mencionado, no se ha podido acceder a un corpus de datos amplio, el análisis ha demostrado que efectivamente existe una sensible variación entonativa entre los enunciados serios y los no serios de un mismo hablante. Dicha diferencia quedaría justificada si apelamos a la afección personal que todo hablante imprime a sus enunciados, tal y como se defiende en textos como Nieto y Otero (2002) o Bryant (2011): "En la conversación oral, la gente transmite muchos mensajes implícitos a través de sus expresiones, tanto verbal como no verbalmente" (Bryant 2011: 291). En la misma línea, de los tres aspectos que configuran la entonación, ha sido el tono el que se ha revelado como más relevante, desde el punto de vista distintivo, algo que concuerda con las ideas de Hidalgo Downing y Nieto y Otero (2014): “[...] la frecuencia [...] es el indicador físico por excelencia para modular la entonación y transmitir los cambios de actitud del hablante, y lograr con ello determinados efectos expresivos" (Hidalgo Downing y Nieto y Otero 2014: 224). La intensidad y el tempo, por su parte, no han mostrado valores lo suficientemente significativos como para considerarlos parámetros relevantes. Todo esto puede apreciarse en la siguiente tabla.

Como vemos, de estos datos se desprende una hipótesis que se desmarca de lo expuesto en la bibliografía: tanto la media como el rango de la f0 (es decir, la amplitud de los movimientos tonales) de la mayoría de los enunciados humorísticos son inferiores a las de los serios ${ }^{20}$. Lo mismo ocurre con la intensidad: en general, los humorísticos se emiten a menor volumen. Y, por último, en lo tocante al tempo, el análisis ha demostrado que la mayoría de los serios se dicen más lentamente que los humorísticos. Todo esto, como se ha mencionado anteriormente, sin que ninguna de estas diferencias sea relevante desde el punto de vista estadístico. En lo que respecta al único chiste de todo el corpus, el tono y la intensidad del cuerpo son mayores que las del remate, que se dice a mayor velocidad que el cuerpo.

20. La única excepción son las dos preguntas retóricas, en donde la f0 obtiene unos valores superiores a los de la f0 de sus contrapartes serias. 
Tabla 1. Comparativa de los parámetros prosódicos entre los enunciados humorísticos y serios del diputado Antonio Miguel Carmona

\begin{tabular}{|c|c|c|c|c|c|}
\hline $\begin{array}{c}\text { Par de } \\
\text { incidencias }\end{array}$ & $\begin{array}{c}\text { Tipo de } \\
\text { incidencia }\end{array}$ & $\begin{array}{l}\text { Rango } \\
\text { f0 }\end{array}$ & $\begin{array}{c}\text { Media f0 } \\
\text { (Hz) }\end{array}$ & $\begin{array}{c}\text { Rango } \\
\text { intensidad } \\
\text { (dB) }\end{array}$ & $\begin{array}{c}\text { Tempo } \\
(\mathbf{s} / \mathbf{s})\end{array}$ \\
\hline \multirow{2}{*}{$\begin{array}{l}\text { 01/12/11 A } \\
\text { Aclaración }\end{array}$} & Humorística & 1,86 & 219,5 & 9,94 & 7,3 \\
\hline & Seria & 2,15 & 259,7 & 16,73 & 6,1 \\
\hline \multirow{2}{*}{$\begin{array}{l}\text { 01/12/11 B } \\
\text { Afirmación }\end{array}$} & Humorística & 2,35 & 190,9 & 10,03 & 6,15 \\
\hline & Seria & 2,69 & 209 & 9,71 & 5,94 \\
\hline \multirow{2}{*}{$\begin{array}{l}01 / 12 / 11 \mathrm{C} \\
\text { Afirmación }\end{array}$} & Humorística & 2,29 & 207,3 & 11,39 & 7,08 \\
\hline & Seria & 2,68 & 225,9 & 14,42 & 5,28 \\
\hline \multirow{2}{*}{$\begin{array}{l}01 / 12 / 11 \mathrm{D} \\
\text { Comentario }\end{array}$} & Humorístico & 2,03 & 173,1 & 7,69 & 7,78 \\
\hline & Serio & 2,54 & 218,9 & 7,9 & 6,71 \\
\hline \multirow{2}{*}{$\begin{array}{l}\text { 06/10/11 A } \\
\text { Orden }\end{array}$} & Humorística & 2 & 226,6 & 7,83 & 5,72 \\
\hline & Seria & 2,61 & 243,1 & 13,52 & 4,05 \\
\hline \multirow{2}{*}{$\begin{array}{l}\text { 06/10/10 B } \\
\text { Preg. Retórica }\end{array}$} & Humorística & 2,57 & 248,3 & 12,74 & 6,58 \\
\hline & Seria & 1,63 & 161,2 & 5,68 & 8,51 \\
\hline \multirow{2}{*}{$\begin{array}{c}03 / 11 / 11 \\
\text { Comentario }\end{array}$} & Humorístico & 1,98 & 177,6 & 10,53 & 4,5 \\
\hline & Serio & 3,7 & 209,4 & 11,03 & 8,36 \\
\hline \multirow{2}{*}{$\begin{array}{c}\text { 06/10/10 C } \\
\text { Exclamación }\end{array}$} & Humorística & 2,74 & 222 & 9,47 & 4,46 \\
\hline & Seria & 2,98 & 295 & 18,08 & 3,72 \\
\hline \multirow{2}{*}{$\begin{array}{c}\text { 10/11/11 } \\
\text { Orden }\end{array}$} & Humorística & 1,86 & 184,6 & 11,87 & 8,29 \\
\hline & Seria & 2,24 & 218,3 & 14,44 & 7,7 \\
\hline \multirow{2}{*}{$\begin{array}{c}\text { 13/10/11 } \\
\text { Aclaración }\end{array}$} & Humorística & 1,4 & 158,2 & 8,68 & 7,07 \\
\hline & Seria & 1,59 & 189 & 18,44 & 5,97 \\
\hline \multirow{2}{*}{$\begin{array}{l}\text { 15/12/11 A } \\
\text { Aclaración }\end{array}$} & Humorística & 3,18 & 150,1 & 14,28 & 8,76 \\
\hline & Seria & 2,37 & 218,8 & 13,72 & 7,92 \\
\hline \multirow{2}{*}{$\begin{array}{c}\text { 15/12/11 B } \\
\text { Preg. Retórica }\end{array}$} & Humorística & 3,17 & 173,5 & 8,88 & 9,12 \\
\hline & Seria & 2,94 & 175 & 9,66 & 7,82 \\
\hline \multirow{2}{*}{$\begin{array}{c}\text { 20/12/11 } \\
\text { Chiste }\end{array}$} & Cuerpo & 2,61 & 224 & 12,26 & 6,51 \\
\hline & Remate & 1,64 & 195 & 5,2 & 8,65 \\
\hline
\end{tabular}

No obstante, a la hora de interpretar estos datos, tal y como se ha mencionado previamente, hay que tener en cuenta dos aspectos: por un lado, las circunstancias ajenas a lo puramente prosódico, tales como la forma de pronunciar del hablante, la calidad de la grabación, la sonoridad de la sala, etc.; por otro, el hecho de que, 
debido a la escasez de análisis que den cuenta en profundidad de la prosodia de los enunciados humorísticos dentro de entornos serios, carecemos de unos baremos precisos sobre los que apoyar este estudio comparativo.

Con respecto a la expresión corporal, los resultados del análisis, que, como se ha indicado, no son lo suficientemente relevantes como para extraer conclusiones sólidas, demuestran que no existen diferencias sensibles entre la gestualización con la que el sujeto seleccionado aborda los enunciados serios y con la que trata los humorísticos. Tal y como se observa en las imágenes siguientes, el diputado Carmona emplea una gesticulación constante y ostentosa a lo largo de todas sus comparecencias. Por lo tanto, esto, más que como pistas paraverbales que el hablante da a su auditorio con la intención de despertar en él una determinada reacción, habría que interpretarlo como manifestaciones de lo que Spencer-Oatey (2008) denomina ethos interaccional, que es la manera en la que interactúan con el entorno los sujetos que participan en una determinada interacción.

a) Exclamación humorística

“'Eso es espionaje!”
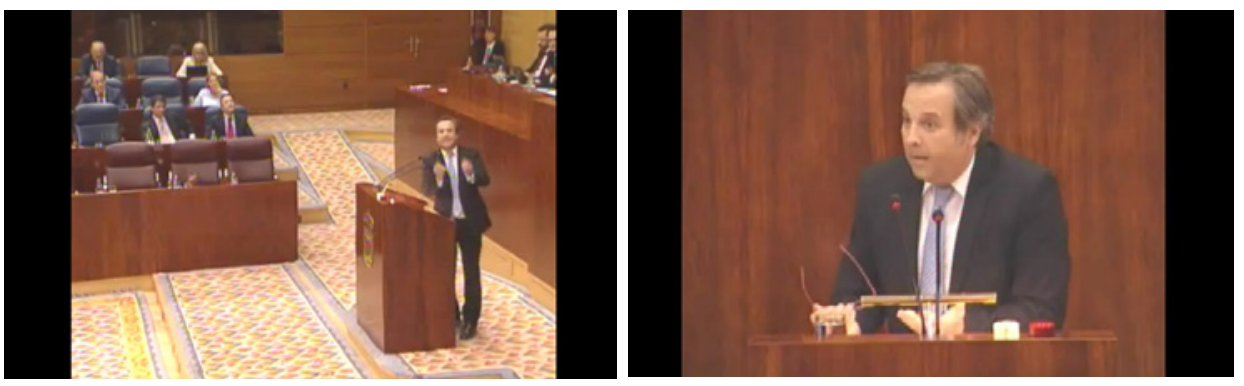

b) Exclamación seria

“¡Hace 200 años!”
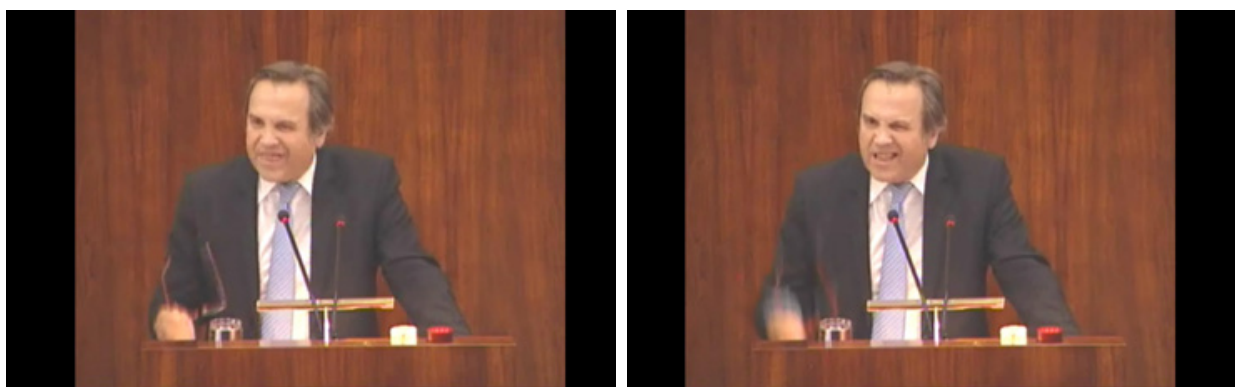

Figura 1. Comparativa gestualidad exclamación humorística / exclamación seria 
Como vemos en estas imágenes, el diputado se mueve y gesticula constantemente a lo largo de sus comparecencias, por lo que no podemos delimitar pistas gestuales claras que sirvan para distinguir sus enunciados humorísticos y no humorísticos.

En líneas generales, se aprecia que el lenguaje gestual del político socialista se caracteriza por tres rasgos cinéticos. El primero de ellos es la tendencia a inclinar el cuerpo hacia su derecha, algo lógico si tenemos en cuenta que se está dirigiendo a los diputados conservadores, sentados en las bancadas de su derecha, lo que demuestra que las palabras del hablante no tienen como destinatario principal al conjunto de la Asamblea, sino únicamente a los diputados del grupo político adversario.

El segundo rasgo cinético son los movimientos de las manos, que en ocasiones son incluso ostentosos, como acreditan las imágenes de la fila superior, correspondientes a la exclamación humorística. En este sentido, es importante observar cómo el hablante sostiene siempre en la mano derecha sus gafas, las cuales únicamente utiliza en las escasas ocasiones en que necesita consultar algún papel, de tal manera que durante la mayor parte de sus intervenciones el diputado socialista emplea este objeto como puntero o señalador que le sirve para dirigirse de manera más precisa a su interlocutor.

Por último, la gestualidad de Carmona se caracteriza por sus histriónicas expresiones faciales, que, como vemos, se dan tanto en la parte humorística como en la seria. En esta línea, son significativas las dos imágenes de la fila inferior, en las que vemos cómo realiza una mueca facial mientras emite una exclamación seria, algo totalmente inesperado en una cámara parlamentaria, donde, como se ha comentado más arriba, se debe mantener una cierta sobriedad tanto en las palabras como en los gestos. Asimismo, es importante añadir que, tal y como nos indica la bibliografía, normalmente las muecas van ligadas a los enunciados lúdicos o humorísticos (Haiman 1990, Attardo et al. 2003) y en consecuencia la expresión facial con la que el diputado socialista acompaña a su exclamación seria no se corresponde con la intención ilocutiva que este ha querido imprimir a sus palabras.

En este par de enunciados vemos cómo el hablante sigue los mismos patrones cinéticos que en el ejemplo anterior: inclinación del cuerpo hacia su interlocutor, gesticulación con las manos, empleo de un elemento señalador, expresiones faciales fuertemente marcadas... Todo ello es la prueba de que el diputado aborda sus discursos en la Asamblea como si se tratase de conversaciones cotidianas, ámbito donde la gesticulación y la deixis hacia el interlocutor juegan un importante papel, demostrando de esta manera un dominio absoluto de la situación comunicativa en la que se encuadra su discurso. 


\section{a) Afirmación humorística}

“En el año 2011 para ustedes las ciudades más importantes del mundo son Nueva York, Parla, París..."
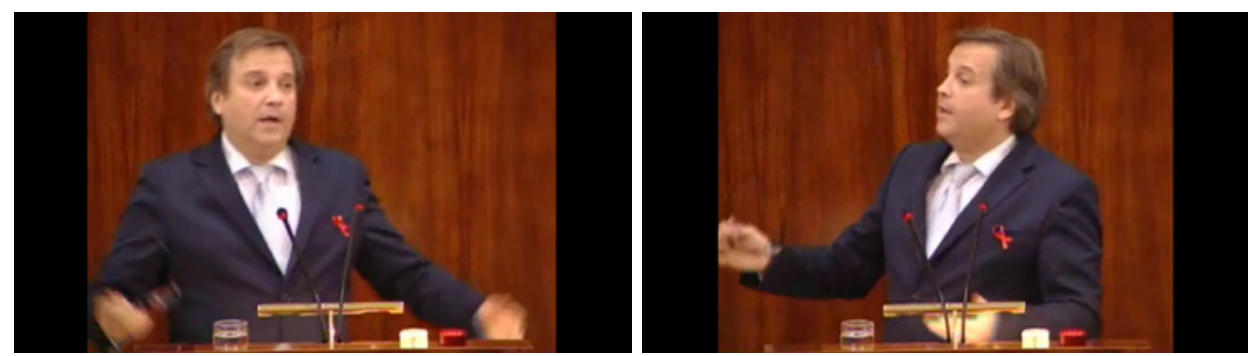

b) Afirmación seria

"No trato de hacer un discurso brillante. Trato de convencerle.

Intelectualmente convencerle."
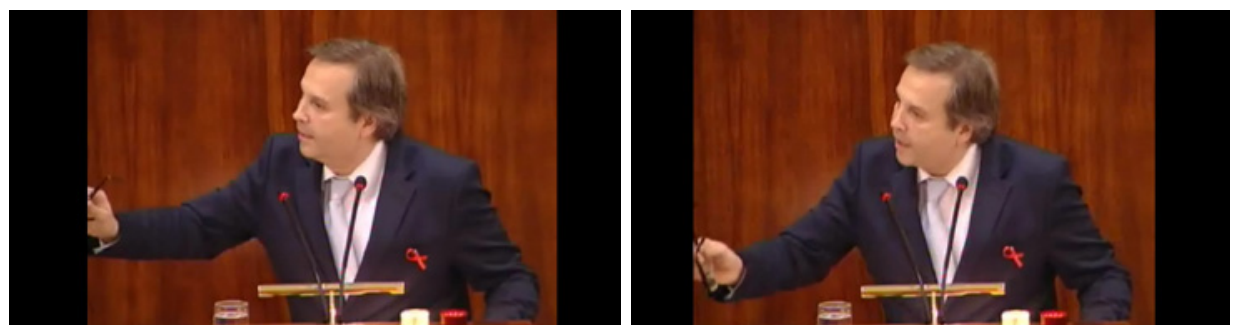

Figura 2. Comparativa gestualidad afirmación seria / afirmación humorística

Por tanto, tal y como se ha indicado más arriba, a la luz de los ejemplos expuestos no podemos extraer patrones cinéticos sólidos que nos permitan distinguir los enunciados serios de los no serios. Por el contrario, debemos considerar que la forma de desenvolverse del diputado Carmona en la Asamblea de Madrid obedece a un determinado ethos interaccional, en la línea defendida por SpencerOatey (2008), es decir, a la forma específica en que un hablante aborda una determinada interacción verbal. Quizá estudios más detallados de otros miembros de la Asamblea arrojarían otros resultados, pero, como ya se ha indicado, solo se ha querido apuntar este tipo de enfoque multimodal.

\section{Conclusiones}

Los resultados obtenidos a partir del análisis prosódico realizado en este trabajo no se han desmarcado demasiado de lo expuesto en la bibliografía: el hablante dife- 
rencia prosódicamente el habla humorística de la seria. Dicha diferencia se aprecia principalmente en la frecuencia fundamental o tono: los enunciados humorísticos presentan patrones tonales anómalos con respecto a los patrones tonales habituales en sus contrapartes serias. Esta diferencia prosódica es especialmente relevante en entornos serios y fuertemente reglados, como los debates parlamentarios, en los que es necesario distinguir prosódicamente el humor si queremos mantener intactos sus efectos comunicativos. Con todo, es necesario un estudio más en profundidad al respecto. En cuanto a la expresión no verbal, también es necesario un análisis exhaustivo, pero de los datos estudiados en este trabajo se desprende que, en los debates parlamentarios, no existe una correlación entre la gestualidad del hablante y la expresión del humor.

\section{Bibliografia}

ACUÑA FERREIRA, V. (2011). "Recursos prosódicos y verbales para la intensificación de las emociones en la conversación cotidiana: ejemplos de su utilización en actividades de queja". Oralia 14: 259-293.

ARCHAKIS, A. y TSAKONA, V. (2011). "Informal Talk in Formal Settings: Humorous Narratives in Greek Parliamentary Debates" en Studies in Political Humor: In between Political Critique and Public Entertainment. (Eds. V. Tsakona y D. Popa). Ámsterdam/Philadelphia: John Benjamins: 61-81.

ATKINSON, M. (1988). Our Masters' Voices. Londres/Nueva York: Routledge. ATTARDO, S. y PICKERING, L. (2011). "Timing in the Performance of Jokes". Humor 24 (2): 233-250.

ATTARDO, S. et al. (2003). "Multimodal Markers of Irony and Sarcasm". Humor 16 (2): 243-260.

ATTARDO, S. et al. (2011). "Prosodic and Multimodal Markers of Humor in Conversation". Pragmatics \& Cognition 19 (2): 224-247.

BECERRA VALDERRAMA, M. I. (2012). "Rasgos prosódicos en la producción de dos formas de ironía en español". Lingüistica 28, 191-205.

BERTRAND, R. y PRIEGO-VALVERDE, B. (2011). "Does Prosody Play a Specific role in Conversational Humor?". Pragmatics \& Cognition 19 (2): 333-356.

BERNÁRDEZ, E. (1984). "El estudio lingüístico textual del chiste. A Textlinguistic Approach to Jokes" en Literary and Linguistic Aspects of Humour: VIth AEDEAN Conference Proceedings. Barcelona: Departamento de Lengua y Literatura Inglesa de la Universidad de Barcelona: 111-116. 
BIRDWHISTELL, R. L. (1979). El lenguaje de la expresión corporal. (Trad. de Antonio Desmonts). Barcelona: Gustavo Gili.

BRYANT, G. (2011). "Verbal Irony in the Wild". Pragmatics \& Cognition 19 (2): 291-309.

BRYANT, G. y FOX-TREE, J. (2002). "Recognizing Verbal Irony in Spontaneous Speech". Metaphor and Symbol 17 (2): 99-117.

BRYANT, G. y FOX-TREE, J. (2005). "Is there an Ironic Tone of Voice?". Language and Speech 48 (3): 257-277.

CABAÑAS MARTÍNEZ, M. J. (2005). "Comunicación no verbal y enseñanza de español como segunda lengua a inmigrantes en contextos escolares". Interlingüistica 16 (1): 225-236.

CESTERO MANCERA, A. M. (2009). "Marcas paralingüísticas y kinésicas de la ironía" en Dime cómo ironizas y te diré quién eres. Una aproximación pragmática a la ironía. (Eds. L. Ruiz Gurillo y X. Padilla García). Frankfurt: Peter Lang: 167-187.

CESTERO MANCERA, A. M. (2015). "La comunicación no verbal: propuestas metodológicas para su estudio". Linred 13.

CHAFE, W. (2007). The Importance of not Being Earnest. Amsterdam/Philadelphia: John Benjamins.

CHARAUDEAU, P. (s. d.). “'Humour quand tu nous tiens'. Essai de definition et de catégorisation du discours humoristique". (Texto inédito).

CHARTERIS-BLACK, J. (2007). The Communication of Leadership. Londres/ Nueva York: Routledge.

CRUCES, F. y DÍAZ DE RADA, Á. (1995). "Representación simbólica y representación política: el mitin como puesta en escena del vínculo electoral". Revista de Occidente 170-171: 163-180.

DAVIS, F. (2010). La comunicación no verbal. Madrid: Alianza Editorial. (Trad. de Lita Mourglier).

FLAMSON, T. et al. (2011). "Prosody in Spontaneous Humor". Pragmatics \& Cognition 19 (2): 248-267.

GARCÍA RIVERÓN, R. (1996-1998). Aspectos de la entonación hispánica (3 Vols.). Madrid: Universidad de Extremadura.

GHIGLIONE, R. (1994). "Paroles de meetings" en Pragmatique du discours politique. (Eds. A. Trognon y J. Larrue). París: Armand Colin: 17-52.

HAIMAN, J. (1990). "Sarcasm as Theater". Cognitive Linguistics 1-2: 181-205. HIDALGO DOWNING, R. (2009). "Políticos y ciudadanos: análisis conversacional de la entrevista política". RELA 8: 89-101. 
HIDALGO DOWNING, R. y NIETO Y OTERO, M. J. (2014). "Estrategias de vinculación afectiva y entonación en un debate político". Oralia 17: 200-235.

HIDALGO NAVARRO, A. (2011). "Humor, prosodia e intensificación pragmática en la conversación coloquial española". Verba 38: 271-292.

LAKOFF, R. (1990). Talking Power. Nueva York: Basic Books.

MUELLER, R. (2011). "Fun in the German Parliament?" en Studies in Political Humour: In between Political Critique and Public Entertainment. (Eds. V. Tsakona y D. Popa). Ámsterdam/Philadelphia: John Benjamins: 33-60.

NIETO Y OTERO, M. J. (2008). La vinculación afectiva en el discurso político. Caracas: Universidad Central de Venezuela.

NORRICK, N. (1993). Conversational Joking: Humor in Everyday Talk. Indiana: Indiana University Press.

PADILLA GARCÍA, X. (2009). "Marcas acústico-melódicas: el tono irónico" en Dime cómo ironizas y te diré quién eres. Una aproximación pragmática a la ironía. (Eds. L. Ruiz Gurillo y X. Padilla García). Frankfurt: Peter Lang: 135-166.

PÉREZ DE AYALA, S. (2001). "FTAs and Erskine May: Conflicting Needs? Politeness in Question Time". Journal of Pragmatics 33: 143-169.

PICKERING, L. et al. (2009). "Prosody Markers of Saliency in Humorous Narratives". Discourse Processes 46 (6): 517-540.

PURANDARE, A. y LITMAN, D. (2006). "Humor: Prosody Analysis and Automatic Recognition for $\mathrm{F} * \mathrm{R} * \mathrm{I} \mathrm{E}^{*} \mathrm{~N} * \mathrm{D} * \mathrm{~S} *$ ". Proceedings of the 2006 Conference on Empirical Methods in Natural Language Processing: 208-215. QUILIS, A. (1993). Tratado de fonología y fonética españolas. Madrid: Gredos. RAO, R. (2006). "On Intonation's Relationship with Pragmatic Meanings in Spanish" en Selected Proceedings of the 8th Hispanic Linguistics Symposium. (Eds. T. Face y C. Klee). Sommerville: Cascadilla Proceedings Project.

SAFTOIU, R. y POPESCU, C. (2014). "Humor as Branding Strategy in Political Discourse. A Case Study from Romania". Signos 47 (85): 293-320.

SPENCER-OATEY, H. (2008). "Face, (Im)politeness and Rapport" en Culturally Speaking: Culture, Communication and Politeness Theory. (Ed. H. SpencerOatey). Londres/Nueva York: Continuum: 11-47.

URIOS-APARISI, E. y WAGNER, M. (2011). "Prosody of Humor in Sex and the City". Pragmatics \& Cognition 19 (3): 507-529.

WICHMANN, A. (2000). Intonation in Text and Discourse: Beginnings, Middles and Ends. Harlow: Pearson Education.

WILSON, J. (1990). Politically Speaking. Oxford: Basil Blackwell. 